\title{
"Liberal education" in the globalizing modernity in the perspective of sustainable development: the experience of philosophical interpretation
}

\author{
Konstantin Maltsev*, Larisa Binkovskaya and Anna Maltseva \\ Belgorod State Technological University named after V.G. Shukhova, Belgorod, Russia
}

\begin{abstract}
Discussion between defenders of preservation of elements of "liberal education" and those who consider it "remnants" (V. Pareto) of the "outdated" model of the "classical university" unfolds in the horizon of the "liberal consensus" regarding the "values" and "goals" of university education in the globalizing reality presented in the economic paradigm (J. Agamben). The prospect of preserving the liberal democratic tradition and the formation of civic "skills of democracy" translates the discussion into a plan of interpreting the meaning of these values and determining the conditions for ensuring their validity. A philosophical interpretation of the essence of liberal values in the context of the foundations of the economic paradigm, which presupposes external criticism, allows us to assert: the distinction between "free" and "professional" education, which is valid for the "university of reason" and has limited significance for the concept of liberal education, is removed in the modern model of the universitycorporation as an enterprise for the production of human capital and practically oriented knowledge/learning aimed at fulfilling the request market for a specialist who has mastered a variety of competencies. The concept of "sustainable development", the constitutive of which in recent years has become the discourse of security, determines a specific explanation of "politicization" (W. Beck), one of which is the defense of "free education", a palliative that corrects the universal and total "monocausal logic of capital" as a real beginning (in the meaning of "à $\rho \chi \eta ́$ ") of global modernity presented in the liberal version of the economic paradigm.
\end{abstract}

\section{Introduction}

The discussion between supporters of "free" university education (also called "liberal") and those who consider the goal of the university to form "competencies" that meet the needs of the globalizing modernity has a long history. For the past twenty years, the defenders of the classical university are clearly in the minority and are on the "defense" of their position they appeal to the values of a liberal society, the reality of which is believed to be largely based on the education of individuals who share its values and were brought up to them, which, in fact, is, in their opinion, the task of the classical university. The

\footnotetext{
*Corresponding author: maltsevaannav@mail.ru
} 
opposition to reality, "monocausal" (W. Beck [1]) by a certain "universal logic of capital" (for example, the same W. Beck, or S. Zizek [2]), and the values of a liberal society, as the horizon of discussion, usually excludes from consideration the issue posed in the $30 \mathrm{~s}$ of the XX century by M. Heidegger, according to whom "the university died in 1890" [3, p. 467], and its death was necessary: in what he calls modernity there is simply no place for a classical university, which was an "intermediate" and "accidental" phenomenon that arose at a time when modernity was still in its infancy. Placing a modern discussion between defenders of "liberal" university education and supporters of the earliest possible disposal of its still existing "remnants" (V. Pareto [4]) hindering the modernization of the university and its integration into the global order in the perspective of interpreting the need for the "death of the university" suggests a philosophical interpretation of the "mission" (J. Ortega y Gasset [5], K. Jaspers [6]) and the fate of the university as a phenomenon excluded from the present and, at the same time, will allow us to compare the meaning of arguments about the purpose and functions, about the form of a modern university, given by the participants in the ongoing discussion.

A specific aspect of the problem: what form shall be given to the university so that it would be one of the most important guarantees of what is called "sustainable development", with the general confidence that this is really the leading issue and a high assessment of the importance of higher education for ensuring such development - formally holds the declared positions in unity and determines the content and direction of the discussion between their supporters.

\section{Study Methodology}

A comparative analysis of the arguments of the participants in the discussion about the essence of modern university education requires the definition of a "common ground" ("middle term"), the presence of which is necessary for the discussion to make sense, and the arguments can be compared in their meaning. The appeal, on the one hand, to values, and on the other, to the requirements of modernity, presupposes the opening of a horizon in which liberal values and modern imperatives can be presented as a consistent unity in some, and precisely essential, respect. The dominant liberal version of the economic paradigm, where reality is universally presented, is equally accepted by both "sides" of the

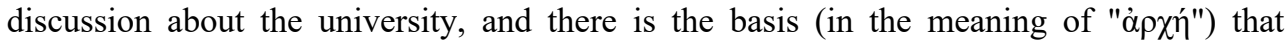
provides the opportunity, content and direction of the discussion: liberal values are shared by all of it participants regardless of their position; the difference is in the way of interpretation. Philosophical interpretation is presented as a method aimed at understanding the meaning of discrimination with essential unity.

\section{Study Results}

M. Heidegger was the first to undertake research on the possibility of a university in modern times; his conclusion is unambiguous: the university is impossible, its "death" is final, any "reanimation" is either the result of the efforts of those who, due to their social status associated with the university, "nostalgic" about its "former meaning" - but this is past; or there is a fake attempt to use the former authority that the university acquired during its heyday, when constructing a fundamentally different educational institution, where only the name remains of the former university ("technical term", as defined by G. Gadamer).

The New European ("Descartesian") subject and the idea of technology as a unity, according to Heidegger, defines the essence of the "last period of modern European 
history" as modernity. The idea of technology, that is, "disclosure of the hidden" as "extractive production", "provision of availability", "extraction, processing, accumulation, distribution, transformation - types of removal from secrecy" [7, p. 227], there is control: "The technical disclosure of the hidden reveals before itself its own intricately intertwined processes by the fact that controls them. Management, for its part, seeks to comprehensively provide for itself' [7, p. 227]. Reality is given in the view of the new European subject in the perspective of "planning-calculated", producing activities, as management aimed at guaranteeing the safety of the subject's current reality.

Modernity is constituted subjectively: "The subjective character of a person - as a modern European - is the deepest historical force" [8, p. 54], - "An era that strengthens its essence the more, the more it thinks only about what it does. However, "it does" only what the fullness of subjectivity should do - self-preservation in the absence of comprehension possibly up to self-destruction" [8, p. 36-37]. The subject has become "its own and only space and time" [8, p. 53], that is, a person "knows that he is a person" and aims to ensure his humanity in its present reality: "A person with everything at his disposal and his own brings all human community and inherited humanity into the underlying basis of all assessments and plans and implementations and makes it possible to lay the basis for measure and purpose and planning as an area" [8, p. 431-432]. Reality is given to the subject in his mind, and the person is completely disposed not to rely on "chance" anymore, but to include everything "without a remainder" in the planning calculation of the mind" [8, p. 178]: "A person knows that he is a person when he is serious about all this possession, profits from it and does not tolerate anything else and justifies any impact by success and everywhere asserts himself as this Subjektum" [8, p. 431-432]. "Closing the transcendent", that is, questionlessness, ends with the triumph of "ensuring life (Lebenssicherung)" [8, p. 432], that is, the security policy provides a way for the existence of a new European subject: "ensuring life", "questionlessness" - this is security, and it is comprehended from the very "essence of subjectivity". Security, that is, calculation and planning, calculability of existence, is the way in which the subject guarantees his validity, with a predetermined outcome/goal. Such a goal is "to one day become part of the machine and, in the service of ensuring the expediency and calculation of its work, to find your easy security, your motives and your lust. This introduction into the machine essence is nothing essentially other than the mere use of "technical" possibilities; here, there is an extreme likening of the essence of man to the calculating (Rechenhaftigkeit) of being. It is with the help of all this that the spirit (i.e. rationality and prudence of animality) and comes to its highest power" [8, p. 416]. Thus, the idea of technology and the new European subject are the same thing that defines modernity.

The task of education is to form the subject's ability to become "a part of the machine", to integrate into it "without residue" and without "contradictions", which means to provide guarantees for the existing existence of the new European subject; or else, to use the terminology popular now: the task of education is the formation of human capital (the "universal logic of capital" with its "monocausality" is one of the projections of the idea of technology that totally determines the modernity). As a matter of fact, the task of a classical university: "preparation of readiness for knowledge" - is not only not "relevant", but simply absent. This was clear not only to Heidegger; J. Ortega y Gasset [5], defining the "mission of the university", argued that "readiness for scientific research" is not the main goal of the university, presenting such "the ability to navigate in life" as a condition for "successful professional activity". The university prepares "professionals" fit for life, that is, for the present; however, Ortega y Gasset believed that this requires the preservation of a certain "level of culture" and, consequently, "cultural skills" (one could say: "general competences"). However, Heidegger also proves that culture itself is a modern phenomenon, which is equally determined by the idea of technology; special "cultural 
tasks" are completely reduced: Heidegger argues that "military service" on the one hand, and "university campus infrastructure" on the other, cope better with this task than a classical university.

Thus, in place of the classical university, a professional technical school is being established (in relation to the idea of technology, the difference between the "natural" and "humanities" sciences is insignificant: the fact that the social sciences, "if they arise", will be natural sciences according to their method, was assumed by G. Rickert [9]; according to Heidegger, modernity has nothing to do with history, and historical knowledge has been replaced by "historiographic recalculation of the past" as modern): "The "Technical Higher School "has long overtaken the "universities"; the latter can survive only by becoming like the former; this assimilation gives rise to a complex of university sciences, gathered around the core - a technical higher school, in the center of which, in turn, is the military-technical faculty" [3, p. 150]. This school is engaged in the production of human capital [10].

It shall be demonstrated that the representation of reality in the liberal version of the economic paradigm does not "contradict" the description of modernity by M. Heidegger (they are so different that they cannot be "directly compared"), but, most importantly, the characteristic features of modernity, defined by Heidegger, are valid for a liberal view of the modern global order. For this, it is sufficient to point out two circumstances.

First: the new European subject and the liberal autonomous individual. Calhoun states: "From the perspective of the modern West, individuals exist in and of themselves: neither networks of relationships nor overarching hierarchy are the primary source of identity. This modern idea of the individual as a locus of indecomposable identity - at least potentially self-sufficient, independent and self-developing..." [11, p. 102], that is, the present individual as a "locus of indecomposable identity" (and methodological individualism justified in this) is a "common place", the evidence of liberal social knowledge. A feature of liberal individualism is that the individual is represented through private interests (personal and group), any group - as associations based on free choice; society - only in the last place as an "association of associations", but above all - as an association of individuals. The discourse of security is "inscribed" into the discourse of liberal freedom through the concept of "liberal values", a consensus that "is not discussed" and which must be defended, including "by the power of institutions". Finally, common interests are defined through "material values" (D. Lal [12]). Concerning "cosmological values", one should assume that they are truly "private" and are not a concern of public education, but a personal matter of everyone. The security of everyone's existence and the protection of his "material interests" is an imperative of security policy and a guarantee of sustainable development.

Second: the idea of technology and formation of human capital. We already pointed out this circumstance at the beginning of the article: the education of an individual should be aimed at his ability to "achieve success," that is, to achieve "material values"; the value of human capital depends on the acquired "competencies". The reality of a liberal society, which is a matter of concern for the supporters of preserving the elements of classical education in a modern university and defending the value of "liberal education", is guaranteed by the correct formation of human capital in a modern university as a "factory for the production of human capital". In fact, the dispute is only about the sufficiency of this guarantee: we are not talking about liberal values per se, but about the formation of skills of "participation in democracy": supporters of classical elements in education argue that such skills are formed sufficiently only as a result of "liberal education". Therefore, the first task of this article has been solved: the absence of a contradiction between "values" and "reality" has been demonstrated; the question for discussion was posed: about the need for "liberal education" for the formation of life skills in a liberal democracy and, most 
importantly, in a liberal global order (it may turn out that for both, different skills are necessary and different "institutional environments" are required for their formation).

\section{Discussion of Results}

The concept of "liberal education" is usually attributed to J. Newman [13]; namely, to his argumentation about the importance of liberal education as formation of readiness for a "free life" in a liberal democratic state that modern defenders of the "university tradition" appeal to and develop. W. von Humbold [14] is also often mentioned "incidentally" as the author of the concept of "research university". Of course, the differences between the "continental" and "insular" traditions of higher university education [15] are significant, but with regard to the subject of our research, they can be "taken out of the brackets". With one exception. Newman argues that theology alone provides the "completion of the system" without which the university remains "headless"; in the concept of "university of reason", the authors of which are I. Kant, I.G. Fichte, F. Schleiermacher and W. von Humboldt, a special case of which is W. von Humboldt's "research university" model, the role played by theology in Newman is attributed to philosophy. However, it is better in this connection to speak not of "completion", but of "foundation." In both cases, the university is considered a "place of knowledge"; However, if in the German version reason, "preparation for which" is university education, is a principle of reality (Fichte expressed it most radically), then in the Newman's concept of "liberal education" emphasis was initially on "preparation for life". In this respect, it is closer to Ortega y Gasset ("university of culture"). The assertion that the American university was originally created as a "research university", giving precisely "liberal education", allows, as we said, in connection with the task of our consideration, not to retain the existing (and in other respects significant) differences in the named concepts. In any case, everything that was said above regarding the "classical university" by M. Heidegger is also important for "liberal education", with the exception of one thing: the initial orientation towards the practice of life in the case when it is shown that this practice requires something different than can give "free education", deprives the latter of the necessary justification, which still remains at the "university of reason" to the extent that reason remains valid even "beyond the boundaries" of the representation of reality in the liberal economic paradigm and the global liberal order (about the meaninglessness and idiocy of which as planetarism Heidegger also wrote). Once again: the dispute about "free education" is not a dispute about "reason", and in this respect it is not a dispute about the "classical university of reason"; it is a dispute about the conditions for preservation of "democracy" and its "values" in the global liberal order.

Newman defines the essence of "liberal education" as follows. First, he asserts that the university is a place for teaching universal knowledge, but not "adding knowledge" [13, p. 10]; he directly states that "the university is not for science" [13, p. 13], that is, of course, for it too, but not in the first place. Secondly, he believes that the purpose of the university is "the cultivation of intelligence" [13, p. 15]: "in a clean and clear atmosphere of thinking" that students "breathe", they "grasp the general outlines of knowledge, the principles on which it is built, the scale of its parts, its light and shadow, strong moments and imperceptible that cannot be understood by others ways" [13, p. 98]. Newman concludes: "Therefore, it turns out that his education is called" liberal"" [13, p. 98], and continues: "The ability of the soul is acquired, which remains for the whole life, the features of which are freedom, justice, tranquility, moderation and wisdom" [13, p. 98]; what Newman calls a "philosophical habit", and considers it "the main purpose of the University" [13, p. 98], education of a liberal citizen; liberal education and liberal aspirations are "an exercise of the soul, reason, thought" [13, p. 102]. Newman is aware of the distinction between education and training; the person himself is educated, - they teach "useful skills": he 
directly states that "liberal education forms a gentleman" [13, p. 112]. The direct task of the university is "the formation of intellectual culture" [13, p. 117], and the goal of intellectual training and, consequently, the university, Newman considers "not learning and assimilation, but thinking and reasoning based on knowledge" [13, p. 127], that is, "what is called philosophy" [13, p. 127]. Thus, liberal education "is a learning process in which the intellect, instead of sacrificing some random or special goal, some craft or profession, or teaching or science, is cultivated for its own sake and for its own higher culture" [13, p. 137].

Thus, university education and vocational training are consistently distinguished; it is necessary to answer the questions: first, what meaning can a "gentleman" have for the reality of modern society and political order, is there a "place" for him; secondly, whether in this connection the "education of a gentleman" is a public matter or is it a completely private matter for everyone (the distinction between "material" and "cultural" values, according to D. Laloux); thirdly, maybe, as Ortega y Gasset believed, a certain form of "gentleman" (culture, for example) is a condition for formation of not only a "citizen", but also a specialist; finally, shall attempts be made to inscribe a set of qualities of a gentleman - in human capital, or the latter, in the realities of the modern global order, in the exact Hegelian sense, removes the opposition between "free" and "professional" education.

The question "why are universities needed?" is the beginning of the discussion on the substantiation of the relevance of "free education" in the book by S. Collini [16], which largely modernizes the argumentation of J. Newman in relation to modern realities; the author argues that the dominant formulation of the question: "It would hardly be an exaggeration to say that in a greater part of today's public debate about universities, it all boils down to the following dismal thesis:

universities need to justify why give them more money, and the only way is to show that they help to make more money" [16, p. 14], - despite its "obviousness" - "inadequate", although it dominates the modern discourse of the university: "Funding", "impact" and "access" - these three starting points, which can be considered either by separately, or, more often, in the form of a trinity designed to demonstrate realism and modernity

someone's position - today they clearly dominate the political and media discussion of universities" [16, p. 15]. It is much more correct to view the university in the "public good" perspective, that is, politically [17]. However, the presentation of politics as management in the liberal economic paradigm determines that most often we are dealing with the "instrumentalist discourse of modern market democracies" [16, p. 21], and Collini regarded as an "inadequate" formulation of the question of the university is a necessary consequence of this discourse. The argument against the dominant "instrumentalism" is formulated as follows: instrumentalist discourse is finite: the question "why?" at some point, it ceases to make sense (he refers to Keynes with his question "why do we need economics?") and can only be of "philosophical interest"; therefore, in order to stay within the boundaries of scientific knowledge, we must accept the idea of "intrinsic benefits" [16, p. 186], to which one should also include "free education" as an element of the general "liberal tradition", and abandon the search for "further justifications". Strictly speaking, this is what the "response" of the defenders of "free education" to their opponents boils down to.

The influence of globalization is also recognized by the defenders of "free education", primarily as a "change in the scale" of activities (scientific, educational) of the university. However, when asked: "Shouldn't we stop thinking in terms of the European ideal of the $19^{\text {th }}$ century?and focus, on the contrary, on why the most powerful implementation of the idea of the university in the XXI century becomes the Asian embodiment of the Americanized version of the European model, so technology, medical and business schools 
come to the fore? " [16, p. 33; 18], - Collini answers rather negatively, believing that "the ubiquitous habit of attaching the adjective" global "to a variety of nouns often indicates only laxity of thought and fashionable hype" [16, p. 34], and supranational modern European science was originally and from the nineteenth century - including "institutionally".

However, if we consider the importance of the university from a political perspective (in terms of "public good"), then in comparison with a classical university, the legitimacy of a modern university is different. This was noticed back in the late 70s of the twentieth century by J.-F. Lyotard: if "earlier" the task of the university was thought of as education and dissemination of a universal model of life, which most often legitimized the story of liberation" [19, p. 117-118], then "now", in the context of "deligitimation", "universities and institutes of higher education are now subject to the requirement of the formation of competencies, and not ideals: so many doctors, so many teachers of a particular discipline, so many engineers, so many administrators, etc. The transfer of knowledge no longer looks like something that is designed to form an elite capable of leading the nation to liberation, but it supplies the system with players capable of ensuring proper performance of the role in practical positions that are required by institutions" [19, p. 118], that is, it is the instrumentalist discourse that is legitimate (they write, for example, about the "McDonaldization of universities" [20].

A systematic vision of the changes that determined the essence of what is now called a university (this name is precisely a "technical term") is presented in the work of B. Readings "University in ruins" [21], published in 1994: the university became a corporation for the production of practically useful knowledge and human capital ("entrepreneurial university": [22]) or, in the perspective of sociological analysis of "modern narratives", there are four "models of the university of the future" [23]; its effectiveness is assessed on a scale of "perfection" [24], which is as close as possible to similar methods of assessing the efficiency of production and work of an enterprise [25], that is, financial efficiency (Heidegger argued that the modern European science, which has become "perfect", that is, "included its own form ", is no different from" machine production", about the related modern problems: [26]. Few doubt that the goal of education, including university education, is the formation of "skills for employment" [27, p. 30], and the competitive "world market of educational services" determines the form of the university and the content of university education $[28$, p. $13 ; 29 ; 30]$.

Newman's fundamental distinction between "free" and "professional" education, which cannot be reduced to the distinction between "mental" and "physical" ("some physical exercises are liberal, but mental activities are not such" [13, p. 102]) is not accidental for correct understanding appealing to the distinction between "freedom" and "slavery" [13, p. 102] no longer attaches importance - in the concept of "human capital" this distinction becomes invalid [31], sometimes the term "social capital" is used [32].

\section{Conclusions}

"Free education" is defended as a tradition; it is presented as an element of "civil culture", the practical significance of which seems more than doubtful; however, in the modern "instrumental discourse of education" built into the "instrumental discourse of modern market democracies", there is a place for it: it can be seen as a tool to reduce pressure on the labor market, as a way to achieve a balance between supply and demand for skilled labor; "Liberal education" is practically useful in this respect, and it is not at all important in what form its "justification" is carried out. Another thing is essential: knowledge as a direct "productive force" (in modern philosophical discussions, more often with reference to Bacon than to Marx) excludes the "university of knowledge" from modernity, totally 
represented in the liberal economic paradigm; moreover, its essential alienation and irrelevance of its "remnants" constitutes an obstacle and a threat to the "universal" monocausal "logic of capital" (although the need to "restrict" it is recognized [Bengtsson; Dalene]. Knowledge and "preparation for knowledge" as the essence of the "university of reason" is presented as a kind of fundamentalism (as not reducible without a trace to interests), and in the discourse of security, as dominating and organizing other "intersecting discourses" and ensuring the coherence, unity of the modern version of the "concept natural development", the earliest possible elimination of these "remnants" is a political imperative.

\section{References}

1. U. Bek, Chto takoe globalizaciya (2001)

2. S. Zhizhek, O nasilii, 184 (2010)

3. M. Hajdegger, Razmyshleniya II-VI, 584 (2016)

4. V. Pareto, Kompendium po obshchej sociologii, 511 (2008)

5. X. Ortega-i-Gasset, Missiya universiteta, 104 (2005)

6. K. Yaspers, Ideya universiteta, 159 (2006)

7. M. Hajdegger, Vopros o tekhnike, Vremya i bytie: Stat'i i vystupleniya, 221-238 (1993)

8. M. Hajdegger, Razmyshleniya VII-XI, 528 (2018)

9. G. Rikkert, Granicy estestvennonauchnogo obrazovaniya ponyatij, 532 (1997)

10. K. Maltsev, L. Binkovskaya and A. Maltseva, Representing «University Education» in the Horizon of the Concept of Sustainable Development and Security Discourse, E3S Web of Conferences, 295, (2021)

11. K. Kalhun, Nacionalizm, 288 (2006)

12. D. Lal, Pohvala imperii: Globalizaciya i poryadok, 364 (2010)

13. Dzh. G. Nyumen, Ideya Universiteta, 208 (2006)

14. W. Humboldt, Uber die innere und aufiere Organisation der hoheren wissenschaftlichen Anstalten in Berlin, Gelegentliche Gedanken uber Universitaten, 273-284 (1990)

15. K. Maltsev, A. Alaverdyan and A. Maltseva, National and State Classical University in a Globalizing Modernity, E3S Web of Conferences, 295, (2021)

16. S. Kollini, Zachem nuzhny universitety? (2016)

17. T. Bourner, A University Education, Action Learning: Research and Practice, 16, 1, 100-104 (2019)

18. M. González-López, M. Pérez-López, L. Rodríguez-Ariza, Clearing the Hurdles in the Entrepreneurial Race: The Role of Resilience in Entrepreneurship Education, Academy of Management Learning \& Education, 18, 3, 457-483 (2019)

19. Z.-F. Liotar, Sostoyanie postmoderna, 160 (1998)

20. C. Olaya, The experimenting university, Kybernetes: The International Journal of Systems \& Cybernetics, 48, 7, 1398-1417 (2019)

21. B. Ridings, Universitet v ruinah, 299 (2010) 
22. W. Vesperi, I. Gagnidze, Rethinking the university system: toward the entrepreneurial university (the case of Italy), Kybernetes: The International Journal of Systems \& Cybernetics, 50, 7, 2021-2041 (2018)

23. A. Alexander, C. Manolchev, The future of university or universities of the future: $a$ paradox for uncertain times, The International Journal of Educational Management, 34, 7, 1143-1153 (2020)

24. M. della Volpe, F. Esposito, Discursive practices about third mission. A survey from Italian universities' official websites, Quality in Higher Education, 26, 2, 224-239 (2020)

25. K. G. Maltsev, A. V. Maltseva, Cifrovizaciya i «cifrovoj fetishizm»: predvideniya v bytijno-istoricheskom myshlenii M. Hajdeggera, CHelovek. Kul'tura. Obrazovanie, 4 (38), 46-58 (2020)

26. L. Harvey, Research fraud: a long-term problem exacerbated by the clamour for research grants, Quality in Higher Education, 26, 3, 243-261 (2020)

27. G. Tomas, Obrazovanie: ochen' kratkoe vvedenie, 176 (2016)

28. D. Salmi, Sozdanie universitetov mirovogo klassa, 134 (2009)

29. R. W. Hall, Creating the Innovative University, Technology \& Innovation, 21, 4, 1-14 (2020)

30. G. Doğan, U. Al, Is it possible to rank universities using fewer indicators? A study on five international university rankings, Aslib Journal of Information Management, 71, 1, 18-37 (2019)

31. K. G. Maltsev, A. V. Maltseva, "Chelovecheskij kapital» kak koncept biopolitiki: opyt filosofskogo istolkovaniya, Izvestiya Yugo-Zapadnogo gosudarstvennogo universiteta, 10 (5), 242-252 (2020)

32. M. Rey-Garcia, V. Mato-Santiso, Enhancing the effects of university education for sustainable development on social sustainability: the role of social capital and realworld learning, International Journal of Sustainability in Higher Education, 21, 7, 1451-1476 (2020)

33. S. Bengtsson, L. Östman, Globalisation and education for sustainable development: exploring the global in motion, Environmental Education Research, 22, 1, 1-20 (2016)

34. D. Swanson, M. Gamal, Global Citizenship Education / Learning for Sustainability: tensions, "flaws», and contradictions as critical moments of possibility and radical hope in educating for alternative futures, Globalisation, Societies and Education, 1-14 (2021) 